\title{
Injuries sustained by users and non-users of gum shields in local rugby union
}

\author{
D.C. Jennings, MB, BS, LRCP, MRCS, DSMSA \\ General Practitioner, Reigate, Surrey, UK
}

This study was undertaken because of the high number of orofacial injuries and the complacent attitude of local rugby union players to the wearing of gum shields in spite of encouragement and advice to do so. Amongst non-users there seemed to be an attitude that injuries are inevitable. This apathy and cavalier attitude to unnecessary injury needs to be changed. These injuries can be almost totally avoided by the use of protective apparatus ${ }^{1}$. An attempt was also made to determine if youngsters were well informed about the benefits of gum shields and if they were in fact wearing them. As it has been found in contact sports that the higher the grade of competition, the greater the risk of a player sustaining injury, a comparison has been made with other studies on elite players. The incidence of injury is thought to increase with age and playing level.

\section{History of gum shields}

The first report of gum shields being worn was in boxing in $1913^{2}$. The shields were curved trays of rubber material held in place by gritting the teeth together. Even then it was realised that this simple device reduced the incidence of knock-outs following blows to the mandible ${ }^{3-5}$ as well as providing local orofacial protection.

Until thirty years ago little consideration was given to the protection afforded by a gum shield. Before 1962, dental injuries accounted for more than 25 to 30 percent of all injuries in American football. At that time, extensive research was undertaken on the use of gum shields in American footballers. These studies showed the value of gum shields in reducing orofacial injuries ${ }^{6}$. In 1969, Hawke and Nicholls reported a survey of orofacial injuries in New Zealand rugby players in which 61.8 percent had sustained injury, only 7.2 percent of whom were wearing a gum shield at the time.

Address for correspondence: D.C. Jennings, Barn Ridge, 18 High Trees Rd, Reigate, Surrey RH2 7ES

This is an edited version of the study submitted for the examination for the Diploma in Sports Medicine of the Society of Apothecaries

(C) 1990 Butterworth-Heinemann Ltd

0306-4179/90/030159-07
Numerous studies have shown between 90 and 100 percent reduction in dental injuries by wearing custom made gum shields ${ }^{4,5,8}$. Myers found no cases of dental injuries and attributed this to the almost universal wearing of gum shields in club and representative teams ${ }^{9}$. Two recent studies of club rugby in England showed that 23.8 percent and 38 percent of players wore gum shields regularly, but that 38.4 percent and 28 percent in these two studies had sustained previous dental injury ${ }^{8,10}$.

Gum shields are now the commonest form of protective device worn in body contact sport, although they are not as universally accepted in English rugby union and league as they are in Australia. Since 1973, all high school and college footballers in the United States have been required to wear gum shields. This is not mandatory at professional level, but most professional footballers wear them.

A gum shield reduces the incidence of direct and indirect injury to the teeth. In addition, it will also protect the lips and cheeks from laceration against the teeth, absorb forces which might fracture the mandibular angle or condyle, and reduce the incidence of brain injury. The latter is brought about by an increase in the distance between the closed position of the mandibular condyles and the skull by two $\mathrm{mm}$ when a gum shield is worn. This lessens the transmission of forces through the condyle to the skull and brain following impact to the mandible. There is also a reduction of forces being transmitted to the cervical spine with a lessening of the risk of cervical cord injury ${ }^{11,12}$.

\section{Methodology}

A retrospective study of orofacial injuries sustained and the incidence of concussion and loss of consciousness suffered by a sample of regular English club rugby players at both senior and mini levels was undertaken. The senior players were from Courage London South West Division 3, and were all the players participating on two Saturday afternoons in March and April 1990. Three clubs were involved with first, second and third team players. Two clubs were Old Boys' clubs at the top of their division, and the other was a Hampshire club which won promotion to the same division next season. The 
sample therefore includes players at both ends of the division and from first to third team levels.

A similar study was carried out at the Surrey County Rugby Football Union Mini Rugby Festival in April 1990 in order to determine the use of gum shields and the attitude to wearing them amongst 11 and 12 year olds. This was the average age at which members of senior teams had started to play rugby regularly.

Two questionnaires were devised, one for gum shield wearers and the other for non-wearers. Similar information was sought as in Chapman's study of Australian and British rugby league teams in $1984^{13}$. These included:

Age

Position (forward or back)

Age when first started playing rugby regularly

Attitude to effectiveness of gum shield

If they wear a gum shield, or tried to wear one

Previous orofacial injuries with or without gum shield

Whether non-wearers became wearers after injury Type of gum shield used

Who influenced the decision to wear a gum shield Willingness of wearers to play without a gum shield

Did they think that a gum shield reduced injury Should the wearing of gum shields be made compulsory.

\section{Results}

A total of 114 rugby players with an average age of 25.4 years completed the questionnaire (Table 1). There were 60 ( 52.6 percent) regular wearers and 54 (47.3 percent) non-wearers. In the mini rugby survey, there were 69 players from the under 11 and under 12 categories who took part, with an average age of 11 years. Of these, 45 (65.2 percent) were wearers and 24 (34.8 percent) were non-wearers (Table 2). This is in contrast to the senior group where the numbers of wearers and non-wearers were about equal. There was no significant difference between wearers and non-wearers according to their playing position in either the senior or junior players, and almost equal numbers of forwards and backs in both sets were wearers and non-wearers.

The average age of the senior wearers was slightly less ( 24.2 years) than the non-wearers ( 26.6 years) but was probably not significant. The age range of wearers was between 19 and 36 years, whereas that of non-wearers was between 19 and 45 years. Seven of these were over 36 and three had been playing for more than 30 years. The longest that a wearer had played was 26 years. The average number of years playing rugby was 12.6 for wearers and 14.5 for non-wearers, even though the wearers on average had started playing slightly earlier at $\mathbf{1 1 . 6}$ years as opposed to 12.1 years.

At 11 years old, the mini rugby players had already been playing an average of 3.1 years. Only 13 of the senior players had played up to three years of regular rugby by the time they had reached 11 years of age. This indicates that boys are starting to play rugby earlier these days albeit in a modified version to introduce them to the game. The average age at which they started to play was 7.9 years, and the average age of starting to wear a gum shield was 8.1 years. This represents a delay of only four years before starting to wear a gum shield.

Unfortunately, in spite of this, 45 percent had already sustained orofacial injuries and 4.3 percent had been concussed or lost consciousness. Of these, 23 with previous orofacial injuries had not been wearing a gum shield. Thus, 59 percent of the injured were not wearing gum shields compared to 41 percent of the injured who were wearing gum shields. However, there are more wearers $(65.2$ percent) than non-wearers (34.8 percent).

The total number of senior players who had sustained previous orofacial injuries was 82 (71.9 percent). Of these, 64 were not wearing gum shields at the time of injury. The remaining 18 were wearing

Table 1. Gum shield survey at Old Boys' matches

\begin{tabular}{|c|c|c|c|}
\hline & Overall & No gum shield & Gum shield \\
\hline $\begin{array}{l}\text { Number in survey } \\
\text { Average age } \\
\text { Average age when started to play regular rugby } \\
\text { Sustained previous orofacial injury } \\
\text { Concussed or unconscious } \\
\text { No previous injury } \\
\text { Not wearing a gum shield when injured } \\
\text { Non-wearers who started wearing a gum shield after injury } \\
\text { Average age when started to wear a gum shield } \\
\text { Average delay in starting to wear a gum shield } \\
\text { Non-wearers advised to wear a gum shield } \\
\text { Non-wearers who had tried a gum shield } \\
\text { Wearers who would } \\
\text { Not play without gum shield } \\
\text { Play reluctantly } \\
\text { Play willingly } \\
\text { Wearing a gum shield reduced injury } \\
\text { Wearing a gum shield should be made compulsory }\end{array}$ & $\begin{array}{l}114 \\
25.4 \mathrm{yr} \\
11.8 \mathrm{yr} \\
82(72 \%) \\
55(48 \%) \\
18(15.8 \%)\end{array}$ & $\begin{array}{l}54 \\
26.6 \mathrm{yr} \\
12.1 \mathrm{yr} \\
64(82 \%) \\
39(50 \%) \\
6(7.7 \%) \\
78(68 \%)\end{array}$ & $\begin{array}{l}60 \\
24.2 \mathrm{yr} \\
11.6 \mathrm{yr} \\
18(30 \%) \\
16(27 \%) \\
12(20 \%) \\
\\
24(31 \%) \\
15.5 \mathrm{yr} \\
4 \mathrm{yr}\end{array}$ \\
\hline
\end{tabular}


Table 2. Gum shield survey at mini rugby festival

\begin{tabular}{|c|c|c|c|}
\hline & Overall & No gum shield & Gum shield \\
\hline $\begin{array}{l}\text { Number in survey } \\
\text { Average age } \\
\text { Average age when started to play regular rugby } \\
\text { Sustained previous orofacial injury } \\
\text { Concussed or unconscious } \\
\text { No previous injury } \\
\text { Not wearing a gum shield when injured } \\
\text { Non-wearers who started wearing a gum shield after injury } \\
\text { Average age when started to wear a gum shield } \\
\text { Average delay in starting to wear a gum shield } \\
\text { Non-wearers advised to wear a gum shield } \\
\text { Non-wearers who had tried a gum shield } \\
\text { Wearers who would } \\
\text { Not play without gum shield } \\
\text { Play reluctantly } \\
\text { Play willingly } \\
\text { Wearing a gum shield reduced injury } \\
\text { Wearing a gum shield should be made compulsory }\end{array}$ & $\begin{array}{l}69 \\
11 \mathrm{yr} \\
7.9 \mathrm{yr} \\
39(56 \%) \\
3(4.3 \%) \\
29(42 \%)\end{array}$ & $\begin{array}{l}24 \\
11 \mathrm{yr} \\
8.3 \mathrm{yr} \\
23(74 \%) \\
2(6.5 \%) \\
8(26 \%) \\
31(45 \%)\end{array}$ & $\begin{array}{l}45 \\
11 \mathrm{yr} \\
7.5 \mathrm{yr} \\
16(36 \%) \\
1(2 \%) \\
21(47 \%) \\
7(23 \%) \\
8.1 \mathrm{yr} \\
0.6 \mathrm{yr}\end{array}$ \\
\hline
\end{tabular}

gum shields. Thus, 78 percent of those with orofacial injuries were not wearing gum shields while 22 percent were. Similarly, 55 (48.2 percent) had previously suffered from concussion or loss of consciousness of whom 39 (71 percent) were not wearing gum shields, while 16 (29.1 percent) were. Only 18 (15.8 percent) of all the senior players had not had a previous orofacial injury or suffered from concussion or loss of consciousness. Twice as many wearers (12) were uninjured as non-wearers (six).

After injury, seven of the mini players and 24 of the senior players became gum shield wearers. Fourteen of the senior players had suffered both orofacial injuries and concussion or loss of consciousness and 10 had orofacial injuries only. A further 30 senior players and $16 \mathrm{mini}$ players had been advised at some time to wear a gum shield.

\section{Types of injury}

The number of recorded injuries sustained by each player was kept to the minimum so as to keep the questionnaire brief. Many players had sustained orofacial injuries on several occasions, but in this study, only one injury per area was recorded.

Amongst the senior players, these injuries included six fractured jaws in three non-wearers and three wearers. There were 52 cuts, many requiring stitches. Thirty-eight of these were sustained by non-wearers and 14 by wearers. Twenty-nine nonwearers had chipped or broken teeth and two had lost a tooth. Six wearers had a chipped or broken tooth, and one had a tooth loosened (Table 3). It is not known whether these teeth were in the upper or lower jaw. As a gum shield only covers the upper teeth and gums, the lower teeth are exposed to injury. Twenty-four non-wearers needed to see a dentist after injury; 19 of these now regularly wear a gum shield.

Many episodes of a concussion are denied at the end of a game. These players do not see a doctor at the time and play again the following week. This is because the Laws of the Game (1984) state that a
Table 3. Senior club rugby players

No gum shield

Gum shield

$\begin{array}{lcc}\text { Minimum number of injuries } & & \\ \text { Mouth } & 24(31 \%) & 11(18 \%) \\ \text { Lips } & 51(65 \%) & 14(23 \%) \\ \text { Teeth } & 42(54 \%) & 8(13 \%) \\ \text { Jaw } & 15(19 \%) & 11(18 \%) \\ \text { Concussion } & 30(39 \%) & 17(28 \%) \\ \text { Loss of consciousness } & 17(22 \%) & 5(8 \%) \\ \text { Type of injury } & & \\ \text { Fracture } & 3(4 \%) & 3(5 \%) \\ \text { Cuts } & 38(49 \%) & 14(23 \%) \\ \text { Chipped or broken tooth } & 29(37 \%) & 6(10 \%) \\ \text { Lost tooth } & 2(3 \%) & 0 \\ \text { Loose tooth } & 1(1 \%) & 1(2 \%) \\ \text { Requiring treatment by } & & \\ \text { Dentist } & 24(31 \%) & 6(10 \%) \\ \text { Doctor } & 11(14 \%) & 10(17 \%) \\ \text { Specialist } & 4(5 \%) & 2(3 \%) \\ \end{array}$

player who suffers a head injury is not allowed to play rugby for three weeks. Most clubs do not have a doctor attending any of their games and certainly not all of them. For the second to fifth teams and Veterans there may not even be a sponge boy or linesman. As a result, there is no one to advise players correctly about whether they have been concussed and when they should play again. Not infrequently they are concussed again in the next game.

The mini rugby players also reported broken and chipped teeth, five (16.1 percent) with no gum shield and two (4.4 percent) with a gum shield (Table 4). One non-wearer lost a tooth. He needed to see a dentist as did two other shield wearers. These players also sustained cuts around the mouth and lips; 15 (48.4 percent) in non-wearers and seven (15.6 percent) in wearers.

The boys' reasons for not wearing a gum shield were divided equally between difficulties with breathing, being uncomfortable, and poor fit. Other reasons given were: 'My front teeth fell out', 'It's in 
Table 4. Mini rugby players

\begin{tabular}{lcc}
\hline & No gum shield & Gum shield \\
\hline $\begin{array}{l}\text { Minimum number of injuries } \\
\text { Mouth }\end{array}$ & $5(16.1 \%)$ & $10(22.2 \%)$ \\
Lips & $14(54.2 \%)$ & $9(20 \%)$ \\
Teeth & $9(29 \%)$ & $4(8.9 \%)$ \\
Jaw & $4(13 \%)$ & $3(6.7 \%)$ \\
Concussion & $1(3.2 \%)$ & $1(2.2 \%)$ \\
Loss of consciousness & $1(3.2 \%)$ & 0 \\
$\begin{array}{l}\text { Type of injury } \\
\text { Fracture }\end{array}$ & 0 & 0 \\
Cuts & $15(48.4 \%)$ & $7(15.6 \%)$ \\
Chipped or broken tooth & $5(16.1 \%)$ & $2(4.4 \%)$ \\
Lost tooth & $1(3.2 \%)$ & 0 \\
Loose tooth & $1(3.2 \%)$ & 0 \\
Requiring treatment by & & \\
Dentist & $1(3.2 \%)$ & $2(4.4 \%)$ \\
Doctor & & $3(6.7 \%)$ \\
Specialist & 0 & 0 \\
\hline
\end{tabular}

Dad's pocket', 'Dad's going to buy me one', and 'I forgot'.

The reasons for not wearing a gum shield were mainly difficulty with breathing and talking followed by discomfort. Twenty-four (46 percent) of the non-wearers had tried to wear a gum shield, 17 had tried a custom-made gum shield, and 23 had tried a self-moulded one. Some had tried both kinds.

Twenty-nine (25.4 percent) senior players had never used a gum shield. The cost of the custommade shield had only deterred four non-wearers. However, another four had lost their gum shields and eight others had varying excuses such as nausea, gagging, asthma, or just 'too old' or 'too lazy'. The wearers were equally divided in their choice of gum shield; 33 shields were custom-made and 27 were self-moulded.

In the junior rugby players, 16 (66.6 percent) of the non-wearers had been advised to wear a gum shield but only one had tried. Most of the wearers $28(62.2$ percent) wore custom-made gum shields (Table 6). This was in part due to a dental service offered to clubs who run mini rugby teams. A dental technician was available to fit all the mini players with gum shields at the start of the season. However, it seems that parents have the greatest influence on the youngster's decision to wear a gum shield: two-thirds were influenced by parents, and one-third by a coach or school teacher. Small boys tend to do as they are told.

Table 5. Reasons for not wearing a gumshield:

\begin{tabular}{|c|c|c|}
\hline & Mini players & Senior players \\
\hline Uncomfortable & 8 & 15 \\
\hline Difficulty breathing & 7 & 23 \\
\hline Poor fit & 7 & 4 \\
\hline Lost & 1 & 4 \\
\hline Cost & 0 & 4 \\
\hline Other & 7 & 8 \\
\hline
\end{tabular}

Table 6. Types of gumshield worn or tried

\begin{tabular}{lcc}
\hline & Non-wearers who had tried & Wearers \\
\hline Seniors: & 17 & \\
Custom-made & 23 & 32 \\
Self-moulded & & 29 \\
Minis: & 4 & 28 \\
Custom-made & 10 & 17 \\
Self-moulded & & \\
\hline
\end{tabular}

The senior wearers indicated that their decision was entirely their own in 71.1 percent of cases. The others were variously influenced by parents, coach, dentist, seeing others injured, or in the case of one player who admitted that he felt 'More of a poser with a gum shield'.

Of the total number of men, 90 (79 percent) thought wearing a gum shield reduced injuries. Of these 34 (63 percent) were non-wearers and 56 (93 percent) were wearers. The youngsters had more faith in the gum shields; 61 (88.4 percent) believed that they reduced injury. Of these 18 (75 percent) were non-wearers and 43 (95 percent) were wearers. Thirty two (28 percent) men and 44 (63.8 percent) boys thought that the wearing of gum shields should be made compulsory. More wearers than nonwearers thought this in both groups: 10 (18.5 percent) and 11 (45.8 percent) of non-wearers, and 22 (37 percent) and 33 (73.3 percent) of wearers for men and boys respectively.

Amongst the wearers, the number of men who would not play without a gum shield was 11 (18 percent) and the number of boys was 18 ( 40 percent). However, ten (22.2 percent) of the boys would play willingly without a gum shield, compared to six (10 percent) of the men. Forty three (72 percent) of the men and 17 (37 percent) of the boys would play reluctantly without a gum shield.

\section{Comparisons}

If this study group is compared with the 1984 Australian rugby union touring team and the 1984 Great Britain rugby league touring team the average age of the players and the average duration of playing are about the same (Table 7). However, 100 percent of both these elite groups of players believed gum shields reduce injuries against 79 percent of the local Old Boys. Despite this, 80 percent of the Wallabies and only 28 percent of the British Tourists actually wore gum shields. Of the Wallabies, 33 percent had sustained previous orofacial injuries compared to 60.7 percent of the British Tourists and 71.9 percent of the local Old Boy players. Seventy-five percent of the Wallabies thought that gum shields should be made compulsory, whereas 28.6 percent of the British Tourists and 36.6 percent of the Old Boys thought this.

The delay in wearing a gum shield from the start of playing was different between elite Australian and British players, being 1.9 years and 9.7 years respectively. The Old Boys' Clubs had a four year delay. In Australia there is more public awareness 
Table 7. Comparison of attitude to gum shields between three levels of players

\begin{tabular}{|c|c|c|c|}
\hline & $\begin{array}{c}1984 \text { Wallabies } \\
\text { (Chapman) }\end{array}$ & $\begin{array}{c}1984 \text { GB rugby league } \\
\text { touring team } \\
\text { (Chapman) }\end{array}$ & $\begin{array}{c}\text { Surrey club } \\
\text { players } 1990 \\
\text { (Jennings) }\end{array}$ \\
\hline $\begin{array}{l}\text { Average age } \\
\text { Average duration of playing career } \\
\text { Average delay before wearing gum shield } \\
\text { Gum shields provide protection } \\
\text { Wearers of gum shields } \\
\text { Wearers of custom-made gum shield } \\
\text { Sustained previous orofacial injury } \\
\text { Sustained previous dental injury } \\
\text { Wearers who believe gum shields should be compulsory }\end{array}$ & $\begin{array}{c}24.9 \mathrm{yr} \\
13.6 \mathrm{yr} \\
1.9 \mathrm{yr} \\
100 \% \\
80 \% \\
95.8 \% \\
33.3 \% \\
20 \% \\
75 \%\end{array}$ & $\begin{array}{l}24.1 \mathrm{yr} \\
13.5 \mathrm{yr} \\
9.7 \mathrm{yr} \\
100 \% \\
25 \% \\
100 \% \\
60.7 \% \\
50 \% \\
28.6 \%\end{array}$ & $\begin{array}{l}25.4 \mathrm{yr} \\
13.6 \mathrm{yr} \\
4 \mathrm{yr} \\
79 \% \\
52.6 \% \\
53.8 \% \\
71.9 \% \\
43.9 \% \\
36.6 \%\end{array}$ \\
\hline
\end{tabular}

and acceptance of gum shields in contact sports although there are more wearers in the national and state teams than club teams ${ }^{14}$.

It is generally thought that the higher the standard of play the more injuries are sustained. In 1985, Chapman showed this when comparing Australian rugby league club, state, and national teams. However, comparison of the Australian rugby league teams with the amateur English club teams does not bear this out (Table 8). There were 71 Australian club players in the study of which 18 (25.4 percent) had received previous orofacial injuries compared to 82 (71.9 percent) of the English players. This is 72.2 percent and 95.1 percent of the non-wearers injured respectively.

As in the previous comparative study, all the Australians believed that gum shields reduced injuries compared to 79 percent of the English. In spite of this, only nine (69.2 percent) of the injured Australians started wearing gum shields after injury. Only 24 (30.8 percent) of the injured English players became wearers. The wearers in both groups had delayed wearing gum shields on average for four years. More of the Australians (75 percent), preferred custom-made gum shields to self-moulded shields compared to the English (59.3 percent). Of those Australians who did wear gum shields regularly, 50 percent were not prepared to play without them, 45 percent would play reluctantly, and only five percent would play willingly without a gum shield. Only 18 percent of the English wearers would not play without a gum shield. The majority (72 percent) would play reluctantly and 10 percent willingly without a gum shield.

Chapman did a further survey on Australian and British rugby league teams in 1986. Only 25 percent of British players wore gum shields compared to 92.8 percent of the Australians ${ }^{15}$. In this study, 60.7 percent of the British team had sustained previous orofacial injuries compared to 35.7 percent of the Australians, a ratio of $1.7: 1$. Combining the two groups, 89.9 percent of those who sustained orofacial injuries were not wearing gum shields at the time.

These studies reinforce the importance of gum shields in contact sports to reduce the risk of orofacial injuries. Not all studies have shown this. Equal numbers of injuries were found in wearers and non-wearers among university students in South Africa $^{16}$. However, most studies do confirm the value of gum shields.

\section{Types of gum shield}

There are three basic types of gum shield: custommade, self-moulded, and stock ready-moulded. They are all worn on the maxillary teeth as they are the most prominent and therefore the most prone to injury. The gum shield provides most protection for

Table 8. Attitudes to gum shields

\begin{tabular}{|c|c|c|}
\hline & $\begin{array}{c}\text { Australian } \\
\text { rugby league team } \\
\text { (Chapman) }\end{array}$ & $\begin{array}{c}\text { English } \\
\text { amateur clubs } \\
\text { (Jennings) }\end{array}$ \\
\hline $\begin{array}{l}\text { Total number } \\
\text { Average age when started playing rugby } \\
\text { Sustained orofacial injury } \\
\text { Injured not wearing gum shield } \\
\text { Effectiveness of gum shield } \\
\text { Currently wearing gum shield } \\
\text { Non-wearers started wearing gum shields after injury } \\
\text { Average age when started wearing gum shield } \\
\text { Average delay in wearing gum shield } \\
\text { Wearers who believed that wearing gum shield should be compulsory } \\
\text { Player who would: } \\
\text { Not play without gum shield } \\
\text { Play reluctantly } \\
\text { Play willingly }\end{array}$ & $\begin{array}{l}71 \\
9.9 \mathrm{yr} \\
18(25 \%) \\
13(72 \%) \\
71(100 \%) \\
40(56.3 \%) \\
9(69 \%) \\
13.9 \mathrm{yr} \\
4 \mathrm{yr} \\
31(77.5 \%) \\
20(50 \%) \\
18(45 \%) \\
2(5 \%)\end{array}$ & $\begin{array}{l}114 \\
11.8 \mathrm{yr} \\
82(72 \%) \\
78(95 \%) \\
90(79 \%) \\
54(47.4 \%) \\
24(31 \%) \\
15.5 \mathrm{yr} \\
4 \mathrm{yr} \\
22(40.7 \%) \\
11(18 \%) \\
43(72 \%) \\
6(10 \%)\end{array}$ \\
\hline
\end{tabular}


the upper anterior teeth. There is still a risk of injury to the lower teeth.

The ideal gum shield should have the following qualities $^{17}$ :

Be comfortable

Good retention

No interference with speech or breathing

Durable for one to two seasons

Affordable

Odourless, tasteless, and non-irritant.

The custom-made type of gum shield conforms best to the ideal ${ }^{17}$. These are moulded in vinyl plastic over individual models of the player's upper teeth. They are fitted by a dentist. They can however be expensive. But the cost of dental treatment following injury could of course be much more than the cost of a custom-made gum shield.

The self-moulded type of gum shield seems to be a popular second choice and is certainly much cheaper. This gum shield comes in only two sizes, which limits the number who can be fitted correctly. It is soaked in hot water before being placed over the upper teeth and moulded while still warm. This type has the added advantage that, if it is left in the pocket and goes through the hot wash, it can easily be remoulded.

The stock ready-moulded gum shield is not recommended since it does not conform to the teeth at all and is therefore difficult to retain without clenching the teeth. It may be such a poor fit that it could be dislodged during play and occlude the airway causing respiratory distress ${ }^{17}$. This is unlikely to happen with a custom-made gum shield.

All the players in this survey who wore gum shields used either a custom-made or self-moulded gum shield. The youngsters had the opportunity of being fitted with a custom-made gum shield at the club at the beginning of each season. Not all clubs have encouraged this and take up of the offer varies considerably. Children need new gum shields every six months as their mouths grow.

The age when a gum shield should first be worn is when children first play organised contact sport at school or in clubs. In the last fifteen years mini rugby has become increasingly popular. This coincides with the increased use of fluoride to prevent dental caries and dentists who have few fillings and extraction to do on bad teeth are turning to expensive orthodontic work. In the youngest age groups, there is little body contact involved, but it does mean that children are playing at a much younger age. It is far more likely that a player will continue to wear a gum shield if he starts early in life $e^{18}$.

Dental injuries in organized contact sport at school cause 15 percent of dental injuries at 13 years, but 50 percent in adolescents ${ }^{19,20}$. Children should be encouraged to use gum shields as early as possi$\mathrm{ble}^{8,21}$. The main reason for not wearing a gum shield is difficulty in breathing and talking. This should not be a problem if it is a good fit and comfortable. Effort is required to obtain a good gum shield, to get used to using it, and not to lose it.

The use of gum shields should be encouraged in training as well as in matches. Injuries can occur during training. The estimated risk ratio of injuries in rugby union competition and training is $4.7: 1^{22}$. Another reason for wearing gum shields during training is to encourage the habit and to improve the ability to breathe and talk with it in and therefore to increase confidence in using it. Most of the breathing and talking difficulties could be overcome with more practice and application, provided that the gum shield is a good fit. 'What you play in, train in.'

A custom-made gum shield is far more likely to fit comfortably. Nausea and gagging can be eliminated by careful fitting and trimming combined with practice in wearing it. Not wearing a gum shield because of asthma may indicate that the asthma is not well controlled or that the player assumes because he has a breathing problem a gum shield is contraindicated. Asthmatics are just as likely to sustain injuries as any other player. Hearsay about gum shields being swallowed or blocking the airway may also cause concern. Being 'too old' to wear a gum shield is no excuse. The incidence of injury increases with age and having managed to avoid injury before does not protect from injury during the next game.

\section{Conclusion}

From this study it would seem that wearing a gum shield to play rugby union is beneficial in reducing the incidence of injuries. There were less injuries to the mouth, lips, and teeth in wearers of gum shields in both groups. The incidence of concussion and loss of consciousness was also less in wearers than non-wearers.

In rugby football it is up to the individual player to make an informed decision about whether to wear a gum shield or not. It would seem that many rugby players are not well informed. Unfortunately, even in the elite groups, who seem more informed of the benefits of wearing a gum shield, the numbers actually wearing them is still unsatisfactory. It is important to educate both the wearers and nonwearers in the benefits of wearing a gum shield. Only 79 percent and 88.4 percent in the two groups of those taking part believed that gum shields reduced injuries and many of these were not aware of the reduction in incidence of concussion and loss of consciousness. In previous studies on elite Australian club players all the participants were aware that gum shields reduce injuries.

It is up to the doctors and dentists to teach the coaches, PE masters, school teachers and parents, so all of them can increase the use of gum shields in young players who will hopefully continue to wear them. Children also learn by example, so their heroes in the elite teams or first school team should wear gum shields. In Australia and America, there is a high rate of use of gum shields and they are generally well accepted. It was not found in this survey that club players had less injuries than national players. The attitude of older players towards gum shields needs to be modified. There is too much complacency and apathy.

Some effort is being made to encourage mini rugby players to wear gum shields but this could be improved. Well organised clubs have a policy of 
recommending gum shields and the coach gives a talk to the players and parents at the start of the season. A few clubs take up the offer of custom-made gum shields for all mini rugby players, but less enforce the wearing of the gum shields. This is partly because the coaches never wore gum shields themselves, or are not fully aware of the benefits. Parents have the biggest influence on instigating the use of gum shields at an early age. Therefore, it is important for the parents to be well informed. They may be more forceful in this after paying for expensive orthodontic treatment. Gum shields are cost effective. Dental treatment is expensive and teeth have a low potential of recovery to normal functional state ${ }^{23}$. Injuries to the teeth demand immediate evaluation and treatment.

Amongst older players, there seems to be resistance to wearing a protective device as this indicates that they are not so brave, are over concerned with their appearance, or worried about sustaining injuries. The days of the front row forward with no front teeth should be over. Surely having no front teeth must detract from their macho image more than wearing a gum shield. There is also a need to study 13 to 18 year olds.

It is hoped that this survey will go some way towards convincing those players who took part that gum shields reduce injuries.

\section{References}

Author please supply complete list of references:

1 Blignaut, J.B., Carstens, I.L. and Lombard, C.J. Injuries sustained in rugby by wearers and nonwearers of mouthguards. Br. J. Sports Med. 1987, 21, 5-7

2 Chapman, P.J. Mouthguards in sport Sport Health 1983, 1, 13-15
3 Chapman, P.J. Orofacial injuries and the use of mouthguards by the 1984 Great Britain Rugby League Touring Team Br. J. Sports Med. 1985a, 19, 34-36

4 Chapman, P.J. Orofacial injuries and mouthguards: a study of the 1984 Wallabies Br. J. Sports Med. 1985b, 19, 93-95

5 Davies, R.M., Bradley, D., Hale, R.W., Laird, W.R.E. and Thomas, P.D. The prevalence of dental injuries in Rugby Players and their attitude to mouthguards $B r$. J. Sports Med. 1977, 11, 72-74

6 De Wet, F.A. The prevention of orofacial sports injuries in the adolescent Int. Dent. J. 1981, 31, 313-319

7 Hawke, J.E. and Nicholas, N.K. Dental Injuries in rugby football N.Z. Dent. J. 1969, 65, 173-175

8 Haywood, J.R. Recent advances in the management of facial fractures Int. Dent. J. 1978, 31, 313-319

9 Heintz, W.D. Mouth protectors: a progress report J.A.D.A. 1968, 77, 632-636

10 Heintz, W.D. Mouth protectors in sports Phys. Sports Med. 1979, 7, 45-46

11 Hughston, J.C. Prevention of dental injuries in sports Am. J. Sports Med. 1980, 8, 61-62

12 Moon, D.G. and Mitchell, D.F. 'An evaluation of a commercial protective mouth piece for football players'. J.A.D.A. 1961, 62, 568-572

13 Myers, P.T. 'Injuries presenting from Rugby Union Football'. Med. J. Aust. 1980, 2, 17-20

14 Nicholas, N.K. 'Dental injuries in primary and intermediate school children' N.Z. Dent. J. 1980, 76, 8-11

15 Stenger, J.M., Lawson, E.A., Wright, J.M. and Ricketts, J. Mouthguards: Protection against shock to the head, neck and teeth J.A.D.A. 1964, 69, 273-281

16 Sugarman, S. Injuries in an Australian Schools Rugby Union Season Aust. J. Sport Med. Exer. Sci. 1983, 15, 5-14

17 Turner, C.H. Mouth protectors. Br. Dent. J. 1977, 143, 82-86

18 Upson, N. 'Dental injuries and the attitudes to mouthguards' Br. J. Sports Med. 1982, 16, 241-244

19 Wehner, P.J. and Henderson, D. Maximum prevention and preservation Dent. Clin. N. Amer. 1965, 9, 493-498 